\title{
Aldehyde dehydrogenase 1 expression correlates with the invasion of breast cancer
}

\author{
Hong Pan ${ }^{1 \dagger}$, Naping Wu ${ }^{1,2+}$, Yaoyu Huang ${ }^{1 \dagger}$, Qin Li ${ }^{1}$, Chenghao Liu' ${ }^{1}$, Mengdi Liang ${ }^{1}$, Wenbin Zhou ${ }^{1 *}$, Xiaoan Liu ${ }^{1}$ \\ and Shui Wang ${ }^{1}$
}

\begin{abstract}
Background: Aldehyde dehydrogenase 1 (ALDH1) is an important marker of tumor-initiating cells. We aimed to investigate ALDH1 expression in benign breast disease and human breast cancer of different histologic stages.

Methods: Immunohistochemical staining of ALDH1 was applied to 21 cases with benign breast diseases, 47 ductal carcinoma in situ (DCIS) cases, 62 cases diagnosed with invasive cancer with extensive intraductal component (EIC), and 58 cases diagnosed with invasive cancer without EIC.

Results: ALDH1 was expressed in tumor cells in $61.0 \%$ of 164 breast cancer cases, which was higher than that in benign breast disease $(3 / 21)(P<0.001)$. Of these 167 breast cancer cases, a significantly higher rate $(54 / 58)$ of intratumoral ALDH1 expression was observed in invasive cancer without EIC cases than that in DCIS cases (19/46, one case not available) and invasive cancer with EIC cases $(27 / 60$, two cases not available) $(P<0.001)$. Interestingly, a significantly higher rate (22/48) of intratumoral ALDH1 expression in invasive component was observed than that in in situ component $(7 / 48)$ in the same tumor $(P=0.001)$. In 47 DCIS cases, no significant association was observed between ALDH1 positivity and any clinicopathological parameter (all $P>0.05$ ). However, ALDH1 positive invasive breast cancers were significantly more likely to be with large tumor size $(P=0.001)$, high grade $(P<0.001)$, and high Ki67 expression $(P=0.009)$.
\end{abstract}

Conclusions: ALDH1 may play an important role in the invasion of breast cancer, and may be associated with aggressive phenotypes of breast cancer.

Virtual slides: The virtual slide(s) for this article can be found here: http://www.diagnosticpathology.diagnomx.eu/ vs/1608671725154947.

Keywords: ALDH1, Breast cancer, DCIS, Invasive cancer

\section{Background}

Breast cancer is a worldwide malignant disease. Recent studies [1-3] suggest that this disease is driven by a subpopulation of breast cancer cells, called breast tumor-initiating cells (BT-ICs), which have been identified with the capacity for self-renewal and the ability to generate different cell types [4]. BT-ICs bear the phenotype of $\mathrm{CD} 44^{+} / \mathrm{CD} 24^{-}$[5], and aldehyde dehydrogenase 1 (ALDH1) is also an important marker of BT-ICs [6]. Ginestier and colleagues have found that ALDH1 may

\footnotetext{
* Correspondence: zhouwenbin_1984@foxmail.com; zhouwenbin@njmu.edu.cn ${ }^{\dagger}$ Equal contributors

'Department of Breast Surgery, The First Affiliated Hospital with Nanjing Medical University, 300 Guangzhou Road, 210029 Nanjing, China
} Full list of author information is available at the end of the article be a better marker of BT-ICs than $\mathrm{CD}_{4} 4^{+} / \mathrm{CD} 24^{-}$in immunodeficient mice [6].

Previous studies $[1,6-8]$ have found ALDH1 positive cancer cells may be associated with aggressive phenotypes and poor clinical outcomes in breast cancer patients. Park and colleagues have attempted to investigate the role of ALDH1 in the progression of breast cancer [9]. They have found ALDH1 positive cells were more frequent in basal-like and HER2+ than in luminal tumors, but no significant difference of ALDH1 expression was observed in four histologic groups (invasive ductal carcinoma (IDC), IDC with ductal carcinoma in situ (DCIS), DCIS with microinvasion, and pure DCIS). However, the ALDH1-positive rate in IDC seems higher than that in DCIS in another study [1]. The previous

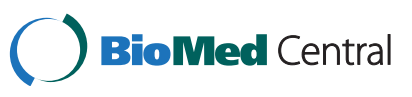


results are discordant, and the cutoffs of positive ALDH1 in different studies are different [1, 6-9].

Furthermore, the normal mammary stem-like cells can also be identified by the expression of ALDH1 [10-12]. Isfoss and colleagues have found a positive association between the frequency of ductular ALDH1 positive cells and several breast cancer risk factors in histologically normal breast tissue [12], which supports previous evidence that ALDH1 may play a role in the development of breast cancer.

In this study, ALDH1 expression was investigated in benign breast disease and human breast cancer of different histologic stages (DCIS, invasive cancer with extensive intraductal component (EIC), and invasive cancer without EIC). Furthermore, the associations between ALDH1 positivity and clinicopathological parameters were also determined.

\section{Methods}

\section{Patients}

The present study was approved by the ethics committee of The First Affiliated Hospital with Nanjing Medical University. Written, informed consent was given by the patients for their information to be used for research. This study was also in compliance with the Helsinki Declaration.

From January 2010 to December 2011, operable breast cancer patients, diagnosed with DCIS, invasive cancer with EIC, and invasive cancer without EIC by using resection specimen, were screened in our hospital. The exclusion criteria included the following: (a) patients treated with neoadjuvant chemotherapy; (b) patients diagnosed with breast cancer by using core biopsy; (c) not enough specimens for further pathological analysis. At last, 167 consecutive breast cancer patients were recruited in this study, including 47 DCIS cases, 62 cases diagnosed with invasive cancer with EIC, and 58 cases diagnosed with invasive cancer without EIC. Furthermore, specimens of 21 benign breast diseases (mastopathy, hyperplasia, and fibroadenoma in this study) were included in this study.

\section{Pathology}

The pathology was reviewed by two experienced pathologists independently. Disagreements were resolved with consensus opinion. The specimens were paraffinembedded for histopathological examinations. Then, $4 \mu \mathrm{m}$ histological sections were cut and stained with hematoxylin and eosin (H\&E). DCIS with microinvasion $\leq 1 \mathrm{~mm}$ was also considered as the DCIS category in our study. EIC was defined as positive if the proportion of DCIS was greater than $25 \%$ of the whole tumor in pathologic sections $[13,14]$.

Immunohistochemical (IHC) analyses on paraffinembedded material were used to determine the status of estrogen receptor (ER), progesterone receptor (PR), Her2, and Ki67. The status of ER, PR, Her2 and Ki67 were determined as described previously $[15,16]$. Low Ki67 expression was defined as positive Ki67 staining $\leq 14 \%$ in pathologic sections, while high Ki67 expression was defined as positive Ki67 staining $>14 \%$. Patients with invasive breast cancer were categorized into triple negative and non-triple negative breast cancer in this study. Triple negative breast cancer was defined as ER, PR and Her2 negative.

ALDH1 status was also determined by IHC. IHC analyses were performed on $4 \mu \mathrm{m}$, formalin-fixed, paraffinembedded slides from breast cancer tissues. Paraffinembedded tissue sections were deparaffinized, rehydrated, rinsed, and immersed in $10 \mathrm{mM}$ sodium citrate $(\mathrm{pH}$ 6.0) for antigen retrieval under high pressure in a pressure cooker for 3 minutes. After treated with methanol containing $3 \%$ hydrogen peroxide for 10 min to block endogenous peroxidase activity, the slides were incubated with mouse monoclonal antibody directed against human ALDH1 (aa 7-128, diluted 1:100; Becton, Dickinson and Company) for 1 hour at $37{ }^{\circ} \mathrm{C}$. After washing, sequential incubations were performed with horseradish peroxidase (HRP) conjugated antibodies (Invitrogen) for $30 \mathrm{~min}$ at room temperature. The stain was visualized using $D A B$ Plus (Dako) and hematoxylin counterstain. Tumor presenting at least one ALDH1-positive cancer cell was considered as an ALDH1-positive tumor, and stroma presenting at least one ALDH1-positive stromal cell was considered as an ALDH1-positive stroma $[1,6]$.

\section{Statistical analysis}

In our study, median, percentiles and range were analyzed for continuous variables. The variables in this study included: age at diagnose, pathology, tumor size, axillary node status, tumor grade, ER, Her2, Ki67, and molecular subtype. Differences between the subgroups with regard to above variables were examined using Fisher's exact test or chi-square test. All $P$-values were two-tailed with $5 \%$ significance levels. All statistical analyses were performed using STATA version 11.0 (Computer Resource Center, America).

\section{Results}

\section{Baseline characteristics}

167 patients with different stages of breast cancer were enrolled in the present study (Table 1), including 47 DCIS cases, 62 cases diagnosed with invasive cancer with EIC, and 58 cases diagnosed with invasive cancer without EIC. The median patient age was 48 years (range, 20-82 years). Of these 167 patients, 58 (34.7\%) were found with axillary node involved, and 114 (68.3 \%) were diagnosed with ER positive breast cancer. Of 120 invasive cancer patients, 27 $(22.5 \%)$ were Her2 overexpressed. 
Table 1 Characteristics of included breast cancer patients

\begin{tabular}{ll}
\hline Variables & Number (\%) \\
\hline Age $(y)$ & $94(56.3 \%)$ \\
$\leq 50$ & $73(43.7 \%)$ \\
$>50$ & \\
Pathology & $47(28.1 \%)$ \\
DCIS & $120(71.9 \%)$ \\
Invasive cancer & \\
Tumor size ${ }^{a}$ & $55(45.8 \%)$ \\
$\leq 2$ cm & $63(52.5 \%)$ \\
$>2$ cm & $2(1.7 \%)$ \\
Not available & \\
Axillary node status & $103(61.7 \%)$ \\
Negative & $58(34.7 \%)$ \\
Positive & $6(3.6 \%)$ \\
Not available & \\
ER status & $53(31.7 \%)$ \\
Negative & $114(68.3 \%)$ \\
Positive & \\
Her2 status ${ }^{a}$ & $93(77.5 \%)$ \\
Negative & $27(22.5 \%)$ \\
Positive &
\end{tabular}

\section{ALDH1 expression in benign breast disease and breast cancer}

ALDH1 protein expression was determined in benign breast disease and breast cancer tissues. Of 21 benign breast disease tissues, ALDH1 was only expressed in epithelial cells in 3 cases; while ALDH1 was expressed in tumor cells in $61.0 \%$ (100/164, three cases not available) of 164 breast cancer cases (Fig. 1). A significant difference was observed between these two groups $(P<0.001)$.

Additionally, ALDH1 was expressed in stromal cells in $89.5 \%$ (17/19, two cases not available) of benign cases; while ALDH1 was expressed in stromal cells in $92.0 \%$ (150/163, four cases not available) of 164 breast cancer cases. There was no significant difference between these two groups $(P=0.702)$.

\section{ALDH1 expression in different stages of breast cancer}

ALDH1 protein expression was determined in different stages of breast cancer, including DCIS, invasive cancer with EIC, and invasive cancer without EIC (Fig. 1). ALDH1 was expressed in stromal cells in $93.5 \%(43 / 46$, one case not available) of DCIS cases, $85.0 \%$ (51/60, two cases not available) of invasive cancer with EIC cases, and $98.2 \%$ (56/57, one case not available) of invasive cancer without EIC cases. The ALDH1 expression rates in stromal cells among these different stages of

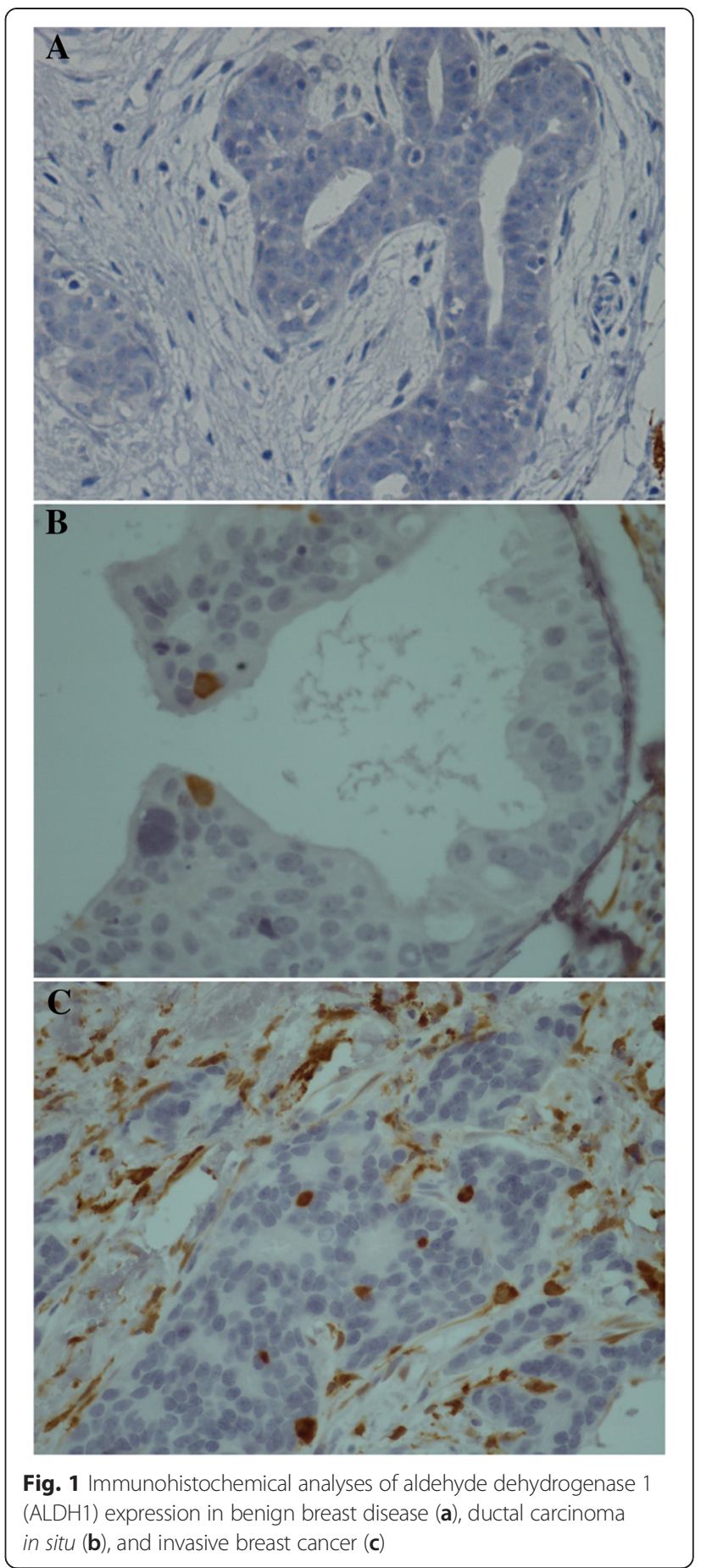

breast cancer were significantly different $(P=0.022$, Table 2).

Interestingly, ALDH1 was expressed in tumor cells in $41.3 \%$ (19/46, one case not available) of DCIS cases, $45.0 \%$ (27/60, two cases not available) of invasive cancer with EIC cases, and $93.1 \%(54 / 58)$ of invasive cancer without EIC cases. A significant difference was observed in these three groups $(P<0.001$, Table 2$)$. 
Table 2 ALDH1 expression in different stages of breast cancer

\begin{tabular}{lcccccccc}
\hline Pathology & \multicolumn{2}{l}{ Stromal ALDH1 } & & \multicolumn{3}{l}{ Intratumoral ALDH1 } \\
\cline { 2 - 3 } & & Negative & Positive & $P$ value & & Negative & Positive & $P$ value \\
\hline DCIS & 3 & 43 & 0.022 & & 27 & 19 & $<0.001$ \\
Invasive + EIC & 9 & 51 & & & 33 & 27 & \\
Invasive & 1 & 56 & & 4 & 54 & \\
\hline
\end{tabular}

\section{Intratumoral ALDH1 expression in DCIS}

The association between intratumoral ALDH1 expression and clinicopathological parameters of DCIS was investigated (Table 3). In these 47 DCIS cases, no significant association was observed between ALDH1 positivity and age $(P=0.528)$, tumor size $(P=0.951)$, grade $(P=0.812)$, ER status $(P=0.428)$, Her2 status $(P=0.536)$, or Ki67 $(P=0.667)$.

Intratumoral ALDH1 expression in invasive breast cancer The relationship between intratumoral ALDH1 expression and clinicopathological parameters of invasive cancer was determined (Table 4). In these 120 invasive cancer cases, no significant association was observed between ALDH1 positivity and age $(P=0.243)$. A significantly higher rate $(53 / 63)$ of intratumoral ALDH1 expression was observed in large tumors $(>2 \mathrm{~cm})$ than that $(30 / 54)$ in small tumors $(\leq 2 \mathrm{~cm})(P=0.001)$. There was a trend that more intratumoral ALDH1 expressed in

Table 3 Relationship between intratumoral ALDH1 expression and clinicopathological parameters of DCIS

\begin{tabular}{|c|c|c|c|}
\hline \multirow[t]{2}{*}{ Variables } & \multicolumn{3}{|c|}{ Intratumoral ALDH1 } \\
\hline & Negative & Positive & $P$ value \\
\hline \multicolumn{4}{|l|}{ Age (y) } \\
\hline$<40$ & 5 & 5 & \multirow[t]{2}{*}{0.528} \\
\hline$\geq 40$ & 22 & 14 & \\
\hline \multicolumn{4}{|c|}{ Tumor size } \\
\hline$\leq 1.5 \mathrm{~cm}$ & 10 & 8 & \multirow[t]{2}{*}{0.951} \\
\hline$>1.5 \mathrm{~cm}$ & 13 & 10 & \\
\hline \multicolumn{4}{|l|}{ Grade } \\
\hline$|-| \mid$ & 9 & 7 & \multirow[t]{2}{*}{0.812} \\
\hline III & 15 & 10 & \\
\hline \multicolumn{4}{|l|}{ ER } \\
\hline Negative & 7 & 7 & \multirow[t]{2}{*}{0.428} \\
\hline Positive & 20 & 12 & \\
\hline \multicolumn{4}{|l|}{ Her2 } \\
\hline Negative & 14 & 11 & \multirow[t]{2}{*}{0.536} \\
\hline Positive & 8 & 4 & \\
\hline \multicolumn{4}{|l|}{ Ki67 } \\
\hline$\leq 14 \%$ & 10 & 9 & \multirow[t]{2}{*}{0.667} \\
\hline$>14 \%$ & 9 & 6 & \\
\hline
\end{tabular}

Table 4 Relationship between intratumoral ALDH1 expression and clinicopathological parameters of invasive breast cancer

\begin{tabular}{|c|c|c|c|}
\hline \multirow[t]{2}{*}{ Variables } & \multicolumn{3}{|c|}{ Intratumoral ALDH1 } \\
\hline & Negative & Positive & $P$ value \\
\hline \multicolumn{4}{|l|}{ Age (y) } \\
\hline$\leq 50$ & 23 & 41 & \multirow[t]{2}{*}{0.243} \\
\hline$>50$ & 14 & 40 & \\
\hline \multicolumn{4}{|l|}{ Tumor size } \\
\hline$\leq 2 \mathrm{~cm}$ & 24 & 30 & \multirow[t]{2}{*}{0.001} \\
\hline$>2 \mathrm{~cm}$ & 10 & 53 & \\
\hline \multicolumn{4}{|l|}{ Grade } \\
\hline$|-| \mid$ & 27 & 36 & \multirow[t]{2}{*}{$<0.001$} \\
\hline III & 4 & 35 & \\
\hline \multicolumn{4}{|l|}{ Axillary node status } \\
\hline Negative & 22 & 38 & \multirow[t]{2}{*}{0.156} \\
\hline Positive & 14 & 43 & \\
\hline \multicolumn{4}{|l|}{ ER status } \\
\hline Negative & 11 & 28 & \multirow[t]{2}{*}{0.604} \\
\hline Positive & 26 & 53 & \\
\hline \multicolumn{4}{|l|}{ Her2 status } \\
\hline Negative & 28 & 63 & \multirow[t]{2}{*}{0.801} \\
\hline Positive & 9 & 18 & \\
\hline \multicolumn{4}{|l|}{ Ki67 } \\
\hline$\leq 14 \%$ & 15 & 21 & \multirow[t]{2}{*}{0.009} \\
\hline$>14 \%$ & 12 & 55 & \\
\hline \multicolumn{4}{|l|}{ Molecular subtype } \\
\hline Triple negative & 6 & 17 & \multirow[t]{2}{*}{0.992} \\
\hline Non-triple negative & 22 & 62 & \\
\hline
\end{tabular}

tumors with involved lymph nodes (43/57) than that without involved lymph nodes (38/60), but no significant difference was observed $(P=0.156)$. Importantly, a significantly higher rate (35/39) of intratumoral ALDH1 expression was observed in grade III tumors than that $(36 / 63)$ in grade I-II tumors $(P<0.001)$.

No significant association was observed between intratumoral ALDH1 positivity and ER status $(P=0.604)$, or Her2 status $(P=0.801)$. Similarly, the frequencies of intratumoral ALDH1 positivity between triple negative and non-triple negative breast cancers were not significantly different $(P=0.992)$. The frequency of intratumoral ALDH1 positive tumors with high Ki67 expression was significantly higher than that with low Ki67 expression $(P=0.009)$.

\section{Intratumoral ALDH1 expression patterns of invasive and} in situ components of the same tumor

To determine if the difference seen in the expression of some markers between invasive and in situ components may reflect a potential divergence in expression associated 
with in situ to invasive breast carcinoma progression, we examined the expression of ALDH1 in tumors with invasive and in situ areas present on the same slides. Of 62 invasive cancers with EIC cases, intratumoral ALDH1 expressions of both invasive and in situ components were available in 48 cases. ALDH1 was expressed in 22 cases in invasive component, and in 7 cases in the in situ component. A significant difference was observed in these two different components of the same tumor $(P=0.001)$. Of these 48 cases, ALDH1 was expressed in both invasive and in situ components in 7 cases. In these 7 cases, a higher percentage of ALDH1 positive tumor cells were observed in invasive component than that in the in situ component in 4 cases.

\section{Discussion}

The purpose of the present study was to investigate ALDH1 expression in cancer cells in human breast cancer of different histologic stages. We found that ALDH1 was expressed in tumor cells in DCIS cases with a lowest rate, and in invasive cancer without EIC cases with a highest rate. Importantly, intratumoral ALDH1 expression in invasive component showed a higher rate of that in the in situ component in the same tumor for the first time. Furthermore, no significant association was observed between ALDH1 positivity and clinicopathological parameters in DCIS cases, while ALDH1 positive invasive breast cancers were significantly more likely to be with large tumor size, high grade, and high Ki67 expression.

In the present study, ALDH1 was expressed in tumor cells in $41.3 \%$ of DCIS cases, $45.0 \%$ of invasive cancer with EIC cases, and $93.1 \%$ of invasive cancer without EIC cases. Charafe-Jauffret and colleagues [8] have found that ALDH1 was expressed in $34 \%$ of inflammatory breast cancer with approximately $3 \%-5 \%$ positively stained cells in these tumors. However, Park and colleagues [9] have found that ALDH1 was expressed in few cases (less than $10 \%$ ) and no significant difference was observed in four histologic groups. To our knowledge, the difference of ALDH1 positivity in different studies may be due to the different cutoffs. In the study of Park [9], less than $10 \%$ with ALDH1 stained was categorized as negative, while only $0 \%$ was categorized as negative in other studies $[1,6,8,12]$. The previous study [1] has shown that only 1 case was ALDH1 positive of 23 DCIS cases, while about $11 \%$ invasive breast cancers were ALDH1 positive. Similarly, the expression of ALDH1 was lower in DCIS compared with IDC in our study. Moreover, one of the most interesting findings of our study is that intratumoral ALDH1 expression in invasive component showed a higher rate of that in the in situ component in the same tumor. All these findings may potentially implicate ALDH1 in the progression to invasion.
Morimoto and colleagues [1] have found that ALDH1 positive breast cancers are significantly more likely to be ER negative, PR negative, Her2 overexpression, and Ki67 positive, but ALDH1 is not significantly associated with poor clinical outcomes. Charafe-Jauffret and colleagues [8] have found that ALDH1 expression correlated with tumor grade, but there was no correlation with other clinical and pathologic features in inflammatory breast cancer. Moreover, previous studies $[6,8]$ have reported that ALDH1 is an independent prognostic marker to predict poor patient outcome in breast cancer. In our study, ALDH1 positive invasive breast cancers were significantly more likely to be with large tumor size, high grade, and high Ki67 expression, but no significant association was observed between ALDH1 positivity and clinicopathological parameters in DCIS cases. All the findings suggest ALDH1 positive cancer cells may be associated with aggressive phenotypes of breast cancer.

In this study, stromal ALDH1 positive cells were detected in most cases, but the frequencies of stromal ALDH1 positivity between benign breast disease and breast cancer were not significantly different. It should be pointed out that reports about human stromal stem cell in benign terminal ductal-lobular unit are limited [17-19]. Isfoss and colleagues [11] have described two morphologically distinct stromal ALDH1 positive cell types in benign mammary tissue from women with and without breast cancer. The most numerous and widely distributed stromal cell type is a spindle-shaped, fibrocytelike cell with slender cytoplasm and a small, elongated nucleus, while the other ALDH1 positive stromal cell type shows a round or oval shape, with a relatively large nucleus. To the best of knowledge, the true identity of the stromal ALDH1 positive cell types is unclear and needs to be elucidated in future studies. In the present study, the high frequencies of stromal ALDH1 positivity among different stages of breast cancer were significantly different. Due to the small sample size, the difference may be attributed to chance. It seems that stromal ALDH1 expression may be involved in different processes in carcinogenesis, but future studies are needed.

Several limitations still exist in our study. First, the expression of ALDH1 in human breast cancer of different histologic stages was focused on in this study, and the prognosis of these cases was not available. Second, the sample size was relative small, and our findings should be confirmed in the future.

\section{Conclusions}

In conclusion, ALDH1 may play an important role in the invasion of breast cancer, and may be associated with aggressive phenotypes of breast cancer. Future studies with large sample size should be needed to confirm our findings. 


\section{Abbreviations}

ALDH1: Aldehyde dehydrogenase 1; BT-ICs: Breast tumor-initiating cells; DCIS: Ductal carcinoma in situ; EIC: Extensive intraductal component; ER: Estrogen receptor; H\&E: Hematoxylin and eosin; IDC: Invasive ductal carcinoma; IHC: Immunohistochemical; PR: Progesterone receptor.

\section{Competing interests}

The authors declare that they have no competing interests.

\section{Authors' contributions}

WZ, XL and SW has contributed to the conception and design of the study, the analysis and interpretation of data, the revision of the article as well as final approval of the version to be submitted. QL, HP, NW and $\mathrm{YH}$ participated in the design of the study, performed the statistical analysis, drafted and revised the article. HP, NW, YH, CL and ML performed the experimental study. All authors read and approved the final version of the manuscript.

\section{Acknowledgements}

This work was supported in part by the National Natural Science Foundation of China (81270952, 81070684, 81071753, 81172502, 81202077 and 81272916), the Natural Science Foundation of Jiangsu Province (BK2011853, BK2011855 and BK20141023), the Program for Development of Innovative Research Team in the First Affiliated Hospital of NJMU (IRT-008) and a project Funded by the Priority Academic Program Development of Jiangsu higher Education Institutions (PAPD).

\section{Author details}

Department of Breast Surgery, The First Affiliated Hospital with Nanjing Medical University, 300 Guangzhou Road, 210029 Nanjing, China. ${ }^{2}$ Department of Breast Surgery, The Third Affiliated Hospital with Suzhou University, 185 Juqian Street, Changzhou 213000, China.

Received: 26 December 2014 Accepted: 19 May 2015

Published online: 13 June 2015

\section{References}

1. Morimoto K, Kim SJ, Tanei T, Shimazu K, Tanji Y, Taguchi T, Tamaki Y, Terada N, Noguchi S. Stem cell marker aldehyde dehydrogenase 1-positive breast cancers are characterized by negative estrogen receptor, positive human epidermal growth factor receptor type 2, and high Ki67 expression. Cancer Sci. 2009;100(6):1062-8.

2. Visvader JE, Lindeman GJ. Cancer stem cells in solid tumours: accumulating evidence and unresolved questions. Nat Rev Cancer. 2008;8(10):755-68.

3. Dalerba P, Cho RW, Clarke MF. Cancer stem cells: models and concepts. Annu Rev Med. 2007:58:267-84

4. Ponti D, Costa A, Zaffaroni N, Pratesi G, Petrangolini G, Coradini D, Pilotti S, Pierotti MA, Daidone MG. Isolation and in vitro propagation of tumorigenic breast cancer cells with stem/progenitor cell properties. Cancer Res. 2005;65(13):5506-11.

5. Al-Hajj M, Wicha MS, Benito-Hernandez A, Morrison SJ, Clarke MF. Prospective identification of tumorigenic breast cancer cells. Proc Natl Acad Sci U S A. 2003;100(7):3983-8.

6. Ginestier C, Hur MH, Charafe-Jauffret E, Monville F, Dutcher J, Brown M, Jacquemier J, Viens P, Kleer CG, Liu S, et al. ALDH1 is a marker of normal and malignant human mammary stem cells and a predictor of poor clinical outcome. Cell Stem Cell. 2007;1(5):555-67.

7. Gong C, Yao H, Liu Q, Chen J, Shi J, Su F, Song E. Markers of tumor-initiating cells predict chemoresistance in breast cancer. PLoS One. 2010;5(12), e15630.

8. Charafe-Jauffret E, Ginestier C, lovino F, Tarpin C, Diebel M, Esterni B, Houvenaeghel G, Extra JM, Bertucci F, Jacquemier J, et al. Aldehyde dehydrogenase 1-positive cancer stem cells mediate metastasis and poor clinical outcome in inflammatory breast cancer. Clin Cancer Res. 2010;16(1):45-55.

9. Park SY, Lee HE, Li H, Shipitsin M, Gelman R, Polyak K. Heterogeneity for stem cell-related markers according to tumor subtype and histologic stage in breast cancer. Clin Cancer Res. 2010;16(3):876-87.

10. Ma I, Allan AL. The role of human aldehyde dehydrogenase in normal and cancer stem cells. Stem Cell Rev. 2011;7(2):292-306.

11. Isfoss BL, Holmqvist B, Alm P, Olsson H. Distribution of aldehyde dehydrogenase 1-positive stem cells in benign mammary tissue from women with and without breast cancer. Histopathology. 2012;60(4):617-33.
12. Isfoss BL, Holmqvist B, Jernstrom $H$, Alm P, Olsson H. Women with familial risk for breast cancer have an increased frequency of aldehyde dehydrogenase expressing cells in breast ductules. BMC Clin Pathol. 2013;13(1):28.

13. Liao N, Zhang GC, Liu YH, Li XR, Yao M, Xu FP, Li L, WU YL. HER2-positive status is an independent predictor for coexisting invasion of ductal carcinoma in situ of the breast presenting extensive DCIS component. Pathol Res Pract. 2011;207(1):1-7.

14. Yiu CC, Loo WT, Lam CK, Chow LW. Presence of extensive intraductal component in patients undergoing breast conservative surgery predicts presence of residual disease in subsequent completion mastectomy. Chin Med J (Engl). 2009;122(8):900-5.

15. Zhou W, He Z, Xue J, Wang M, Zha X, Ling L, Chen L, Wang S, Liu X. Molecular subtype classification is a determinant of non-sentinel lymph node metastasis in breast cancer patients with positive sentinel lymph nodes. PLoS One. 2012;7(4), e35881

16. Zhou W, Pan H, Xia T, Xue J, Cheng L, Fan P, Zhang Y, Zhu W, Xue Y, Liu X Ding Q, Liu Y, Wang S. Up-regulation of S100A16 expression promotes epithelial-mesenchymal transition via Notch1 pathway in breast cancer. J Biomed Sci. 2014;21(1):97.

17. Van Voss MR H, van der Groep P, Bart J, van der Wall E, Van Diest PJ. Expression of the stem cell marker ALDH1 in the normal breast of BRCA1 mutation carriers. Breast Cancer Res Treat. 2010;123(2):611-2.

18. Van Voss MR H, van der Groep P, Bart J, van der Wall E, Van Diest PJ. Expression of the stem cell marker ALDH1 in BRCA1 related breast cancer. Cell Oncol (Dordr). 2011;34(1):3-10.

19. Huang M, Li Y, Zhang H, Nan F. Breast cancer stromal fibroblasts promote the generation of CD44 + CD24- cells through SDF-1/CXCR4 interaction. J Exp Clin Cancer Res. 2010;29:80.

\section{Submit your next manuscript to BioMed Central and take full advantage of:}

- Convenient online submission

- Thorough peer review

- No space constraints or color figure charges

- Immediate publication on acceptance

- Inclusion in PubMed, CAS, Scopus and Google Scholar

- Research which is freely available for redistribution 